\title{
Resin-Based Composite and LCU-related Factors Affecting the Degree of Cure. A Literature Review: Part 2. Light Curing Units \& Related Factors
}

\author{
Aldossary Mohammed ${ }^{1}$, Santini Ario ${ }^{1,2^{*}}$ \\ ${ }^{1}$ MClinDent, University of Edinburgh, UK \\ 2 University of Medicine and Pharmacy Tirgu Mures, Romania
}

Keywords: Quartz Tungsten Halogen Lamps, Light Emitting Diode Units, Light Emitting Diode Units

Received: 08 August 2015 / Accepted: 15 September 2015

\section{Light Curing Units}

In parallel with developments in resin based composite technology, there have been changes in light curing units (LCU). Broadly, there are four categories of LCUs available in the market, with the two commonest used in Dentistry being quartz tungsten halogen $(\mathrm{QTH})$ lamps and light emitting diode (LED) units, though now, QTH is infrequently used in most developed countries.

Argon-ion lasers and Plasma-arc lamps (PALs) had many disadvantages limiting their use. Argon-ion lasers were large devices with increased cost compared to QTHs, [1] PALs had low curing efficiency, increased shrinkage and micro leakage due to fast curing, [2] increased cost, heat and power consumption and decline of lights power output over time compared to QTHs $[1,3,4]$. Because of their limitations, neither LCU have been in regular use in clinical dentistry and therefore will not be discussed further.

\section{Quartz Tungsten Halogen Lamps (QTHs)}

QTHs were the first units to be developed and remained in common use for many years. They had spectral wavelength range of $370-550 \mathrm{~nm}[2,5,6]$, with a spectrum peak of 465-470 nm, matching the absorption peak of CQ [1, 7] QTHs were available with a power intensity of 300-800 $\mathrm{mW} / \mathrm{cm}^{2}$ (milliwatts per square centimeter).

QTHs emit the light when an electric current flows through heated tungsten filament which surrounded by halogen gas. Because these filaments acted as resistors to the passage of electric current, heat was generated [1]. Filters were used to restrict the light to the blue region required for composite polymerization [8].

While relatively low cost technology, they were inefficient, with long curing times needed, produced a lot of waste energy in the form of heat, required the use of fans, and tended to have a short service life as a result of bulb, reflector and filter degradation [3]. QTHs have now been superseded by the more efficient LED LCUs.

\section{Light Emitting Diode (LED) Units}

LEDs produce blue light without filters through using a semiconductor material system (gallium nitride). They produce less heat with low power consumption [3] a longer working life when compared to QTH LCUs. They emit light in a very narrow spectral range, have high efficiency and can be battery- powered cordless units without the need for fans $[9,10]$. LED LCU's are now widely used in clinics because of their advantages over other types of unit. There have been many advances in development through three generations. This will be discussed more in the following Section.

\section{Light Emitting Diode (LED) Units}

The first generation of LED units (1999-2002) had an optimal emission between 440 and $500 \mathrm{~nm}$ with a maximum wavelength at $465-470 \mathrm{~nm}[1,3,7]$. The first generation had a low power intensity range of $100-400 \mathrm{~mW} / \mathrm{cm}^{2}$ $[4,7,10]$.

Most studies in that period compared these LEDs to QTHs and demonstrated inferior curing efficiency when compared to QTH [6].

The second generation of LED (2002-2004) had a higher intensity range of $500-1400 \mathrm{~mW} / \mathrm{cm}^{2}[4,7]$ and cured composite equivalently, or better, than QTH in a shorter time

[11-13]. Composites containing CQ could therefore be cured with these lights. However, a mismatch was reported between the emission spectrum of these units (420$490 \mathrm{~nm}$ ) and other photoinitiators such as TPO and PPD (around 380-410 $\mathrm{nm}$ ) resulting in inadequate curing of the material $[1,14,15]$. In an attempt to address this, and ensure that the RBCs containing these photoinitiators were optimally cured, dual peak LED light curing units, with an additional emission peak around $400 \mathrm{~nm}[1,16-$ 
19] were introduced in the third generation LED LCUs (2004-current).

Dual peak LED LCUs produced high irradiance of $1000-3000 \mathrm{~mW} / \mathrm{cm}^{2}$ and precaution was raised regarding material shrinkage and heat production with this very high intensity [4].

Relatively few studies have investigated the effect of using different types of LED LCU's in relation to the type of incorporated photoinitiators on the curing of RBCs. This can be quite difficult since manufacturers commonly do not state the photoinitiators used in their RBC products [19,20].

\section{LCUs and their effect on the Properties of Resin-Based Composites}

Mechanical and physical properties of composite materials include flexural strength $(\sigma)$, flexural "modulus of elasticity" (E-flexural); both of which are macromechanical properties, and hardness and indentation modulus $(E)$ both of which are micromechanical [21]. Other properties such as polymerization shrinkage, microleakage, marginal integrity and creep deformation $(\mathrm{Cr})$ were investigated in the literature.

Many of these properties of composite materials have been investigated to ensure good performance of the material. Inadequate curing of RBCs is known to affect the mechanical, physical and chemical properties of the material, for example, water absorption, solubility, discoloration, wear resistance, dimensional stability, strength and hardness, all of which can result in the failure of a restoration $[22,23]$. The degree of conversion (DC) has been acknowledged as being vital to the clinical success of these materials which is crucial in determining the mechanical performance of the material and other physical properties [24].

\section{Degree of Conversion (DC)}

As previously noted, composite polymerization results in the monomer molecules being converted into a polymer chain. The degree of conversion (DC) of a material is the extent to which the monomer is converted into a polymer [25] and is quoted as the percentage of double $\mathrm{C}=\mathrm{C}$ bonds within the monomer which convert to a single $\mathrm{C}-\mathrm{C}$ bond.

In the literature, $\mathrm{DC}$ has been shown to vary from $40 \%$ to $80 \%$ in polymerized RBCs [26-29].

While resulting in many improved physical properties, an increase in DC will also increase the polymerization shrinkage stress with an adverse effect on marginal leakage. Therefore, several workers have recommended that the DC be increased to a percentage that balances optimum physical properties with polymerization shrinkage $[6,9]$.

The minimum DC required for composite success clinically has still to be established but is suggested to be at least $55 \%[6,30]$. The DC has a maximum possible rate which will not improve when increasing the total energy level of irradiance from the LCUs [4] and will never be 100\% [31,32].

Several factors have been found to influence the degree of cure and are broadly classified into material-related,
LCU-related or the technique of the clinician. These will be discussed in the following Section.

\section{Material-related Factors Affecting the Degree of Cure}

Some factors related to RBC materials will affect the degree of cure. These are related to monomers and photoinitiators used in these materials. The light transmission through a material will subsequently affect the degree of cure.

\section{Monomers}

The type, volume and viscosity of the monomer have been found to affect the degree of cure and thus, mechanical properties. In the literature, increasing the diluent EGDMA and TEGDMA was found to increase the degree of cure $[28,33,34]$ while an increase in the content of BisGMA resulted in a decrease in the degree of cure $[34,35]$. Using UDMA in a RBC showed a higher degree of cure when compared to Bis-GMA [6]. It is therefore necessary to make a careful balance of monomer to achieve optimum properties.

\section{Photoinitiators}

Several authors have shown that increasing the concentration of photoinitiators in the material will improve the degree of cure [36-39]. This will be only beneficial up to specific thresholds [40] and also may increase yellowing when CQ is used [38,39].

Also, the various types of photoinitiators have been found to affect the degree of cure. TPO molecules showed higher degree of cure than CQ/amine $[6,15,41,42]$ especially when cured by dual peak LED LCUs $[18,28]$ PPD showed no significant difference in the degree of cure compared to CQ when cured with a LED LCU but not with a QTH LCU when it showed a lower degree of cure $[43,44]$. PPD, when used in combination with CQ, resulted in a higher degree of cure compared to each of them when used alone [22]. However Brandt [44] found no difference in the degree of cure when using PPD/CQ together, or each one separately.

For this reason, in order to achieve better polymerization, it is important to identify the absorption spectrum of the photoinitiator used in the RBC and to match it with the LCU used [45].

\section{Light Transmission Through the Resin-Based Com- posite}

During polymerization, the intensity of light is known to decrease with transmission through the RBCs [46-49]. Many factors such as filler load and size, shade, opacity, translucency and material thickness can affect light transmission. These factors are overlapped and will be discussed within the following Sections.

\section{Filler}

Filler type, size and loading will affect the degree of cure by altering light transmission [1]. For filler type, the adding 
of reinforced fillers like hydroxyapatite showed an increase in light transmission through the material, which in turn resulted in higher surface hardness [50] conversely, light transmission was found to decrease with increasing filler content and filler size, because of the scattering effect of the fillers at larger size $[28,51,52]$ also reported a negative effect of mismatching of the refractive index between monomer and filler on light transmission.

\section{Shade and Opacity}

Several workers have reported that darker shades and increased opacity were found to cause energy attenuation and diminished light through transmission [53-55] which resulted in reduced curing of the material $[51,56]$.

\section{MaterialThickness}

Because the light transmission will decrease with increasing thickness, two $\mathrm{mm}$ increments were recommended as the maximum thickness to achieve an adequate depth of cure [57-59].

Regarding the dimension, in vitro, narrow specimens with same thickness showed reduced light transmission when compared to wider samples. This was thought to be because of the absorption of light by mold wall $[60,61]$.

\section{LCU-related Factors Affecting the Degree of Cure}

\section{Type of LCU}

It is important to match the absorption spectra of the photoinitiator with the emission spectra of the LCU $[8,43,62,63]$ In other words, beside the importance of receiving sufficient total energy, this energy must be delivered in the wavelength range which matches the absorption range of the photoinitiator used in the RBCs [64].

It is uncommon for manufacturers to state the photoinitiators used in their RBC products $[19,20]$. Therefore, besides considering other factors, a specific LCU may perform differently when used with different brands of RBCs [64].

\section{Total Energy: Intensity and Exposure Time}

The total energy $\left(\mathrm{J} / \mathrm{cm}^{2}\right)$ is the result of irradiance intensity $\left(\mathrm{mW} / \mathrm{cm}^{2}\right)$ and exposure time (seconds).

Increasing the total light energy has been found to enhance the degree of cure and will therefore promote superior physical properties of the RBCs $[1,65,66]$. The total en ergy delivered to RBC materials can be affected by the power of the unit, curing time, activation modes and the surface area of the material to be cured [67].

Increasing the time of curing has been found to influence material curing when a 20 seconds exposure is used compared to 40 seconds [68] but no further improvement was found if the time was increased to 60 seconds $[69,70]$ keeping in mind the adverse effect on pulp of temperature rise because of the heat. With the development of LED units, composite can be effectively cured in 20 seconds [6].
Also, the total energy delivered will be affected by different light activation modes. These modes were introduced in attempt to improve polymerization and overcome the shrinkage stress, [9] reducing heat effects and to achieve better marginal integrity [4]. Examples of different modes are soft-start, which will use low irradiance first and followed by higher irradiance, step-curing, oscillating irradiation, high intensity, gradual or standard.

It was shown in the literature that light curing modes had a significant effect on the total energy and so the degree of cure [71]. The most important factor is the total energy which delivered to the material to determine its degree of cure [72-74].

The light guide tip diameter has an influence on the efficiency of curing lights. Decreasing the tip diameter will result in increasing the light intensity which will affect the total energy and thus the degree of cure [75]. However, the scattering angle becomes wider so the light intensity will decrease more rapidly with increasing the distance to the topsurface.

\section{Distance of the LCU Tip to the Surface of the Restora- tion}

The degree of curing will be decreased as the distance increases from the tip of the LCU to the composite's surface because the light intensity will be reduced $[71,76,77]$. With variations in accessibility, cusp size and shape of cavities in posterior teeth, it may be difficult clinically to place the light tip on the composite surface. However, Rode [76] recommended that the distance should not exceed $3 \mathrm{~mm}$ to sufficiently cure $2 \mathrm{~mm}$ layer of composite. Other studies only found an effect if the distance was more than 4 $\mathrm{mm}[78]$ or more than $6 \mathrm{~mm}[6,10]$.

In the literature, Price [49] reported a reduction of the light intensity with a parallel light guide to $50 \%$ and even $23 \%$ with a Turbo (smaller) light guide if the distance to the surface was $6 \mathrm{~mm}$.

\section{Total EnergyConcept}

The total energy $\left(\mathrm{J} / \mathrm{cm}^{2}\right)$ is the result of irradiance intensity $\left(\mathrm{mW} / \mathrm{cm}^{2}\right)$ and exposure time (second). There is almost full agreement in the literature about the total energy concept which states that the result of multiplying intensity by curing time should always result in same total energy, thus increasing intensity and reducing time, or decreasing intensity and increasing time can result in the same total energy delivered to the restoration surface. However, there is some question about the validity of reciprocity for combinations of irradiance and time particularly high irradiance and short time $[41,61,66]$.

The total energy required to achieve sufficient polymerization is widely controversial in the literature and recent findings of literature in the area are summarized in Table I.

With the LCU's development, manufacturers produced increased intensity units which resulted in the ability to decrease the curing time. This needs more investigation 
as it may increase the polymerization shrinkage and stress [73].

In the literature, there are many techniques to measure degree of cure (including direct measurement of degree of conversion; DC), and techniques to measure the light intensity and transmission. These techniques will be discussed in the following Sections.

\section{Measuring the Degree of Cure}

Both indirect and direct methods have been reported for measuring the degree of cure of a RBC. Microhardness tests indirectly measure the degree of cure while vibrational (molecular) spectroscopy, by measuring degree of conversion, provides a direct measurement. Other less popular techniques include differential thermal analysis (DTA), differential scanning calorimetry (DSC) and nuclear magnetic resonance (NMR). The following Sections will discuss Vibrational Spectroscopy and Microhardness Tests as they are the more widely used techniques quoted in studies.

\section{Vibrational Spectroscopy}

Vibrational Spectroscopy assesses the DC directly by measuring both the percentage of carbon-carbon single bonds in the cured material and the percentage of unreacted carbon-carbon double bonds [79]. This is the result of measuring the ratio of absorbance area (intensities) of aliphatic $\mathrm{C}=\mathrm{C}\left(\right.$ peak at $\left.1640 \mathrm{~cm}^{-1}\right)$ to aromatic $\mathrm{C}-\mathrm{C}($ peak at 1610 $\left.\mathrm{cm}^{-1}\right)$. The latter is an internal standard before and after composite curing [80]. To calculate the DC, the following calculation (formula) is used:

\section{$\mathrm{DC}=[1-$ Rcured $/$ Runcured $] \mathrm{X} 100$}

Where $\mathrm{R}$ is the peak intensity ratio at $1640 \mathrm{~cm}^{-1}$ and $1610 \mathrm{~cm}^{-1}$ in cured and uncured materials.

Vibrational spectroscopy can be classified to two techniques. The first technique is Fourier Transform Infrared Spectroscopy (FTIR) which is sometimes documented as

Table I. Recommended total energy required for sufficient curing in the literature

\begin{tabular}{lcc}
\hline Author & \multicolumn{1}{c}{$\begin{array}{c}\text { Total } \\
\text { energy }\end{array}$} & $\begin{array}{c}\text { Thickness of } \\
\text { material }\end{array}$ \\
\hline Lee and Greene, 1994 & $>12 \mathrm{~J} / \mathrm{cm} 2$ & $2 \mathrm{~mm}$ \\
Rueggeberg et al. 1994a & $21-24 \mathrm{~J} / \mathrm{cm} 2$ & $2 \mathrm{~mm}$ \\
Sobrinho et al. 2000 & $>12 \mathrm{~J} / \mathrm{cm} 2$ & $2 \mathrm{~mm}$ \\
Yap and Seneviratne, 2001 & $8-16 \mathrm{~J} / \mathrm{cm} 2$ & $2 \mathrm{~mm}$ \\
Yoon et al., 2002 & $6-12 \mathrm{~J} / \mathrm{cm} 2 \mathrm{up}$ to 18 & $1.5 \mathrm{~mm}$ \\
Fan et al. 2002 & $>5-15 \mathrm{~J} / \mathrm{cm} 2$ & $2 \mathrm{~mm}$ \\
Emami and Soderholm, 2003 & $>17 \mathrm{~J} / \mathrm{cm} 2$ & $2 \mathrm{~mm}$ \\
Da Silva et al., 2008 & $>24 \mathrm{~J} / \mathrm{cm} 2$ & $2 \mathrm{~mm}$ \\
Calheiros et al,. 2008 & $>8 \mathrm{~J} / \mathrm{cm} 2$ & $2 \mathrm{~mm}$ \\
Howard et al. 2010 &
\end{tabular}

Infrared Spectroscopy (IR) and is based on light absorption. The second technique, Raman spectroscopy is based on light scattering. There are two devices which are popularly used; Fourier transform-Raman spectroscopy (FTRaman) and micro- Raman spectroscopy(MRS).

\section{Microhardness Test}

This test basically works by loading a known force (in grams) via a diamond indenter to the top or bottom surface of the sample for a specific time (in seconds). The commonest indenters used in the literature are the Knoop $(\mathrm{KHN})$ and the Vickers $(\mathrm{VH})$ indenters, both of which are easy to use. Studies have reported a high correlation between microhardness and DC $[34,81,82]$.

Microhardness tests indirectly measure the degree of cure $[82,83]$ by measuring ratio of the bottom to top surface values [84]. It was reported as an adequate curing when the ratio is at least $0.80(80 \%)$ [82]. In other words, it should be no more than $20 \%$ difference between hardness values of top and bottom surfaces.

\section{Measuring Light Intensity and Light Transmission}

The two most widely used techniques to measure the light intensity of LCUs have used radiometers or an integrating sphere (Spectroradiometer). More recently, a relatively new device, the Managing Accurate Resin Curing (MARC) became popular in studies because it can measure light intensity and light transmission through a material to the bottom surface. These three techniques will be discussed further.

\section{Radiometers}

Portable, hand-held dental radiometers are inexpensive and simple to use. Radiometers have many disadvantages. Their accuracy was reported to be sensitive to the diameter of the light guide tip $[85,86]$. In addition, they cannot continuously monitor the light output over the irradiation time [83]. Also, they only indicate the existence emitting tip irradiance and not the irradiance of the light cure unit when held at a distance from the radiometer [2].

In light of these limitations, their main use has been limited to the periodic monitoring of LCU performance on clinic $[78,87]$.

\section{Integrating Sphere (Spectroradiometers)}

The Integrating Sphere measures all light irradiance output from LCU by defining the light emission area independent of the diameter of the light guide used and the light scattering characteristic [2]. It is a ball-shape device, and the LCU activated inside this ball and measures all the light irradiance shining inside it regardless of the tip diameter, light divergence or scattering.

They are valid and used to determine precise light intensity and these accurate measures are used mainly for research purposes. However, they are expensive, large and bulky which make them unsuitable for clinical use. 


\section{Managing Accurate Resin Curing (MARC ${ }^{\circledR}$ )}

This is an analytic system which allows the amount, type and rate of energy and irradiance delivery to the top surface of resin material specimens to be controlled and measures how much and what type of energy passes through to the bottom surface of the same increment of resin material [36].

MARC $^{\oplus}$ uses integrated calibrated optic probes (energy sensors), connected to a laptop computer, to measure the irradiance, total energy, exposure time. These parameters are recorded by customized software on the computer and the time needed to deliver a specific total energy is calculated. In contrast to the Radiometer, it is possible to measure, and record, changes in light energy delivery in real-time throughout the duration of curing [2]. Its accuracy and reproducibility have been verified experimentally [36].

Two versions of this system are available. First is the MARC ${ }^{\ominus}$-PS (Patient simulator), in which the sensors are embedded in plastic teeth in a mannequin head to simulate and obtain clinically relevant measurements.

The second is a bench-top style unit, the MARC ${ }^{\bullet}$-RC (Resin calibrator), in which the sensor is located on the top surface of the unit. It is designed to allow testing of the light Transmission properties of a material in addition to the light energy of the LCU, but gives no simulation to the clinical environment.

The software measures spectral emission $(\mathrm{nm})$ and the irradiance $\left(\mathrm{mW} / \mathrm{cm}^{2}\right)$ and calculates the total energy $(\mathrm{J} /$ $\mathrm{cm}^{2}$ ) delivered to a simulated restoration based on precise curing time.

\section{References}

1. Santini A. Current status of visible light activation units and the curing of light- activated resin-based composite materials. Dent Update. 2010;37,214-6,218-20,223-7.

2. Rueggeberg FA. State-of-the-art: dental photocuring-a review. Dent Mater. 2011;27,39-52.

3. Mills RW., Jandt KD., Ashworth SH. Dental composite depth of cure with halogen and blue light emitting diode technology. $\mathrm{Br}$ Dent J. 1999;186,388-91.

4. Pelissier B., Jacquot B., Palin WM., Shortall AC. Three generations of LED lights and clinical implications for optimizing their use. 1: from past to present. Dent Update. 2011;38,660-2,664-6,668-70.

5. Neumann MG., Schmitt CC., Ferreira GC., Correa IC. The initiating radical yields and the efficiency of polymerisation for various dental photoinitiators excited by different light curing units. Dent Mater. 2006;22,576-84.

6. da Silva EM., Poskus LT., Guimaraes JG., de Araujo Lima Barcellos A., Fellows CE. Influence of light polymerisation modes on degree of conversion and crosslink density of dental composites. J Mater Sci Mater Med. 2008;19,1027-32.

7. Rahiotis C., Patsouri K., Silikas N., Kakaboura A. Curing efficiency of highintensity light-emitting diode (LED) devices. J Oral Sci. 2010.;52,187-95.

8. Rueggeberg F. Contemporary issues in photocuring. Compend Contin Educ Dent Suppl. 1999;S4-15.

9. Hofmann N., Hugo B., Klaiber B. Effect of irradiation type (LED or QTH) on photo- activated composite shrinkage strain kinetics, temperature rise, and hardness. Eur J Oral Sci. 2002;110,471-9.

10. Lindberg A., Peutzfeldt A., van Dijken JW. Curing depths of a universal hybrid and a flowable resin composite cured with quartz tungsten halogen and light-emitting diode units. Acta Odontol Scand. 2004;62,97-101.

11. Shortall AC. How light source and product shade influence cure depth for a contemporary composite. J Oral Rehabil. 2005;32,906-11.

12. Campregher UB., Samuel SM., Fortes CB., et al. Effectiveness of secondgeneration light-emitting diode (LED) light curing units. J Contemp Dent
Pract. 2007;8,35-42.

13. Mills RW., Uhl A., Blackwell GB., Jandt KD. High power light emitting diode (LED) arrays versus halogen light polymerisation of oral biomaterials: Barcol hardness, compressive strength and radiometric properties. Biomaterials. 2002;23,2955-63.

14. Ikemura K., Ichizawa K., Yoshida M., Ito S.\& Endo T. UV-VIS spectra and photoinitiation behaviors of acylphosphine oxide and bisacylphosphine oxide derivatives in unfilled, light-cured dental resins. Dent Mater J. 2008;27,765-74.

15. Arikawa H., Takahashi H., Kanie T. \& Ban S. Effect of various visible light photoinitiators on the polymerisation and color of light-activated resins. Dent Mater J. 2009;28,454-60.

16. Ilie N., Hickel R. Can CQ be completely replaced by alternative initiators in dental adhesives? Dent Mater J. 2008;27,221-8

17. Busemann I., Lipke C., Schattenberg A., Willershausen B., Ernst CP. Shortest exposure time possible with LED curing lights. Am J Dent. 2011;24,37-44.

18. Price RB., Fahey J., Felix CM. Knoop hardness of five composites cured with single-peak and polywave LED curing lights. Quintessence Int. 2010a;41,e181-91.

19. Sim JS., Seol HJ., Park JK., et al. Interaction of LED light with coinitiatorcontaining composite resins: effect of dual peaks. J Dent. 2012;40,83642.

20. Alvim HH., Alecio AC., Vasconcellos WA., et al. Analysis of camphorquinone in composite resins as a function of shade. Dent Mater. 2007;23,1245-9.

21. Czasch P.\& llie N. In vitro comparison of mechanical properties and degree of cure of bulk fill composites. Clin Oral Investi. 2013;17,227-35.

22. Ferracane JL., Mitchem JC., Condon JR., Todd R. Wear and Marginal Breakdown of Composites with Various Degrees of Cure. Journal of Dental Research. 1997;76,1508-1516.

23. Park YJ., Chae KH.\& Rawls HR. Development of a new photoinitiation system for dental light-cure composite resins. Dent Mater. 1999;15,1207.

24. Moore BK., Platt JA., Borges G., Chu TM., Katsilieri I. Depth of cure of dental resin composites: ISO 4049 depth and micro-hardness of types of materials and shades. Oper Dent. 2008.;33,408-12.

25. Borges BC., Bezerra GV., Mesquita A.,et al. Effect of irradiation times on the polymerisation depth of contemporary fissure sealants with different opacities. Braz Oral Res. 2011;25,135-42.

26. Davidson-Kaban SS., Davidson CL., Feilzer AJ., de Gee AJ., Erdilek N. The effect of curing light variations on bulk curing and wall-to-wall quality of two types and various shades of resin composites. Dent Mater. 1997;13,344-52.

27. Knezevic A., Tarle Z., Meniga A., et al. Degree of conversion and temperature rise during polymerisation of composite resin samples with blue diodes. J Oral Rehabil. 2001;28,586-91.

28. Santini A., Miletic V., Swift MD., Bradley M. Degree of conversion and microhardness of TPO-containing resin-based composites cured by polywave and monowave LED units. J Dent. 2012;40,577-84.

29. Ferracane JL. Correlation between hardness and degree of conversion during the setting reaction of unfilled dental restorative resins. Dent Mater. 1985;1,11-4.

30. Silikas N., Eliades G., Watts DC. Light intensity effects on resin- composite degree of conversion and shrinkage strain. Dent Mater. 2000;16,292-6.

31. Lohbauer U., Rahiotis C., Kramer N., Petschelt A., Eliades G. The effect of different light-curing units on fatigue behavior and degree of conversion of a resin composite. Dent Mater. 2005;21,608-15.

32. Shin DH.\& Rawls HR. Degree of conversion and color stability of the light curing resin with new photoinitiator systems. Dent Mater. 2009;25,10308.

33. Peutzfeldt A. Resin composites in dentistry: the monomer systems. Eur J Oral Sci. 1997;105,97-116.

34. Calheiros FC., Daronch M., Rueggeberg FA., Braga RR. Degree of conversion and mechanical properties of a BisGMA: TEGDMA composite as a function of the applied radiant exposure. J Biomed Mater Res B Appl Biomater. 2008;84,503-9.

35. Floyd CJ., Dickens SH. Network structure of Bis-GMA- and UDMAbased resin systems. Dent Mater. 2006;22,1143-9.

36. Price RB., Mcleod ME., Felix CM. Quantifying light energy delivered to a Class I restoration. J Can Dent Assoc. 2010b;76,a23.

37. Peutzfeldt A., Asmussen E. Hardness of restorative resins: effect of camphorquinone, amine, and inhibitor. Acta Odontol Scand. 1989;47,229-31.

38. Kalliyana Krishnan V., Yamuna V. Effect of initiator concentration, exposure time and particle size of the filler upon the mechanical properties of a 
light-curing radiopaque dental composite. J Oral Rehabil. 1998;25,74751.

39. Rueggeberg FA., Ergle JW., Lockwood PE. Effect ofphotoinitiator level on properties of a light-cured and post-cure heated model resin system. Dent Mater. 1997;13,360-4.

40. Yoshida K., Greener EH. Effect of photoinitiator on degree of conversion of unfilled light-cured resin. J Dent. 1994;22,296-9.

41. Leprince JG., Hadis M., Shortall AC., et al. Photoinitiator type and applicability of exposure reciprocity law in filled and unfilled photoactive resins. Dent Mater. 2011;27,157-64.

42. Miletic V., Santini A. Micro-Raman spectroscopic analysis of the degree of conversion of composite resins containing different initiators cured by polywave or monowave LED units. J Dent. 2012;40,106-13.

43. Neumann MG., Miranda WG. jr., Schmitt CC., Rueggeberg FA., Correa IC. Molar extinction coefficients and the photon absorption efficiency of dental photoinitiators and light curing units. J Dent. 2005;33,525-32.

44. Brandt WC., Schneider LF., Frollini E., Correr-Sobrinho L., Sinhoreti M. Effect of different photo-initiators and light curing units on degree of conversion of composites. Braz Oral Res. 2010;24,263-70.

45. Palin WM., Senyilmaz DP., Marquis PM., Shortall AC. Cure width potential for MOD resin composite molar restorations. Dent Mate. 2008;24,108394.

46. Myers ML., Caughman WF.\& Rueggeberg FA. Effect of restoration composition, shade, and thickness on the cure of a photoactivated resin cement. J Prosthodont. 1994;3,149-57.

47. Lazarchik DA., Hammond BD., Sikes CL., Looney SW.,Rueggeberg FA. Hardness comparison of bulk-filled/transtooth and incrementalfilled/occlusally irradiated composite resins. The Journal of Prosthetic Dentistry. 2007;98,129-140.

48. Ogunyinka A., Palin WM., Shortall AC.,Marquis PM. Photoinitiation chemistry affects light transmission and degree of conversion of curing experimental dental resin composites. Dent Mater. 2007;23,807-13.

49. Price RB., Murphy DG., Derand T. Light energy transmission through cured resin composite and human dentin. Quintessence Int. 2000;31,659-67.

50. Arcis RW., Lopez-Macipe A., Toledano M., et al. Mechanical properties of visible light-cured resins reinforced with hydroxyapatite for dental restoration. Dent Mater. 2002;18,49-57.

51. Thome T., Steagall W. Jr., Tachibana A., Braga SR., Turbino ML. Influence of the distance of the curing light source and composite shade on hardness of two composites. J Appl Oral Sci. 2007;15,486-91.

52. Shortall AC., Palin WM., Burtscher P. Refractive index mismatch and monomer reactivity influence composite curing depth. J Dent Res. 2008;87,84-8.

53. Caughman WF., Rueggeberg FA.\& Curtis JW. Jr. Clinical guidelines for photocuring restorative resins. J Am Dent Assoc. 1995;126,1280$2,1284,1286$

54. Guiraldo RD., Consani S., Consani RL., et al. Light energy transmission through composite influenced by material shades. Bull Tokyo Dent Coll. 2009;50,183-90.

55. Alshali RZ., Silikas N.\& Satterthwaite JD. Degree of conversion of bulk-fill compared to conventional resin-composites at two time intervals. Dent Mater. 2013;29,e213-7

56. Jeong TS., Kang HS., Kim SK.,et al. The effect of resin shades on microhardness, polymerisation shrinkage, and color change of dental composite resins. Dent Mater J. 2009;28,438-45.

57. Rueggeberg FA., Caughman WF., Curtis JW. Jr.\& Davis HC. Factors affecting cure at depths within light-activated resin composites. Am J Dent. 1993;6,91-5.

58. Pilo R., Oelgiesser D.\& Cardash HS. A survey of output intensity and potential for depth of cure among light-curing units in clinical use. J Dent. 1999;27,235-41.

59. Yap AU. Effectiveness of polymerisation in composite restoratives claiming bulk placement: impact of cavity depth and exposure time. Oper Dent. 2000;25,113-20.

60. Harrington E.\& Wilson HJ. Depth of cure of radiation-activated materialseffect of mould material and cavity size. J Dent. 1993;21,305-11.

61. Hadis MA., Shortall AC.\& Palin WM. Specimen aspect ratio and light transmission in photoactive dental resins. Dent Mater. 2012;28,1154-61. 62. Stansbury JW. Curing dental resins and composites by photopolymerisation. J Esthet Dent, 2000;12,300-8.

63. Unn WJ.\& Bush AC. A comparison of polymerisation by light- emitting diode and halogen-based light-curing units. J Am Dent Assoc. 2002;133,335-41.

64. Price RB.\& Felix CA. Effect of delivering light in specific narrow bandwidths from 394 to $515 \mathrm{~nm}$ on the micro-hardness of resin composites. Dent Mater. 2009;25,899-908.

65. Rueggeberg FA., Caughman WF.\& Curtis JW. Jr. Effect of light intensity and exposure duration on cure of resin composite. Oper Dent. 1994a;19,26-32.

66. Peutzfeldt A.\& Asmussen E. Resin Composite Properties and Energy Density of Light Cure. Journal of Dental Research. 2005;84,659-662.

67. Abate PF., Zahra VN.\& Macchi RL. Effect of photopolymerisation variables on composite hardness. J Prosthet Dent. 2001;86,632-5.

68. Lindberg A., Peutzfeldt A.\& van Dijken JW. Effect of power density of curing unit, exposure duration, and light guide distance on composite depth of cure. Clin Oral Investig. 2005;9,71-6.

69. Leloup G., Holvoet PE., Bebelman S.\& Devaux J. Raman scattering determination of the depth of cure of light-activated composites: influence of different clinically relevant parameters. J Oral Rehabil. 2002;29,510-5.

70. Ceballos L., Fuentes MV., Tafalla H., et al. Curing effectiveness of resin composites at different exposure times using LED and halogen units. Med Oral Patol Oral Cir Bucal. 2009;14,E51-6.

71. Zhu S.\& Platt J. Curing efficiency of three different curing modes at different distances for four composites. Oper Dent. 2011;36,362-71.

72. Leprince JG., Lamblin G., Devaux J., et al. Irradiation modes' impact on radical entrapment in photoactive resins. J Dent Res. 2010;89,1494-8.

73. Emami N.\& Soderholm KJ. How light irradiance and curing time affect monomer conversion in light-cured resin composites. Eur J Oral Sci. 2003; 111,536-42.

74. Halvorson RH., Erickson RL.\& Davidson CL. Energy dependent polymerisation of resin-based composite. Dent Mater. 2002/18,463-9.

75. Nitta K. Effect of light guide tip diameter of LED-light curing unit on polymerisation of light-cured composites. Dent Mater. 2005/21,217-23.

76. Rode KM., Kawano Y.\& Turbino ML. Evaluation of curing light distance on resin composite microhardness and polymerisation. Oper Dent. 2007;32,571-8.

77. Pires JA., Cvitko E., Denehy GE.\& Swift EJ. Jr. Effects of curing tip distance on light intensity and composite resin microhardness. Quintessence Int. 1993;24,517-21. 78.RUEGGEBERG F. A. \& JORDAN D. M. Effect of light-tip distance on polymerisation of resin composite. Int J Prosthodont. 1993;6,364-70.

79. Pianelli C., Devaux J., Bebelman S.\& Leloup G. The micro-Raman spectroscopy, a useful tool to determine the degree of conversion of light-activated composite resins. J Biomed Mater Res. 1999;48,675-81.

80. de Santis A., Baldi M. Photo-polymerisation of composite resins measured by micro-Raman spectroscopy. Polymer. 2004;45,3797-3804.

81. Rueggeberg FA., Craig RG. Correlation of parameters used to estimate monomer conversion in a light-cured composite. J Dent Res. 1988;67,932-7.

82. Bouschlicher MR., Rueggeberg FA., Wilson BM. Correlation of bottomto-top surface microhardness and conversion ratios for a variety of resin composite compositions. Oper Dent. 2004;29,698-704.

83. Shortall AC., Harrington E., Wilson HJ. Light curing unit effectiveness assessed by dental radiometers. J Dent. 1995a.;23,227-32.

84. Aguiar FH., Braceiro A., Lima DA., Ambrosano GM., Lovadino JR. Effect of light curing modes and light curing time on the microhardness of a hybrid composite resin. J Contemp Dent Pract. 2007;8,1-8.

85. Leonard DL., Charlton DG., Hilton TJ. Effect of curing-tip diameter on the accuracy of dental radiometers. Oper Dent 1999;24,31-7.

86. Roberts HW., Vandewalle KS., Berzins DW.\& Charlton DG. Accuracy of LED and halogen radiometers using different light sources. J Esthet Restor Dent. 2006;18,214-22; discussion223-4.

87. Hansen EK.\& Asmussen E. Reliability of three dental radiometers. Scand J Dent Res. 1993;101,115-9. 